CLINICAL STUDY

\title{
Gender, smoking during pregnancy and gestational age influence cord leptin concentrations in newborn infants
}

\author{
Simon Kayemba-Kay’s, Michael P P Geary ${ }^{2}$, Jane Pringle, Charles H Rodeck ${ }^{1}$, John C P Kingdom ${ }^{3}$ \\ and Peter C Hindmarsh \\ London Centre for Paediatric Endocrinology and Metabolism at Institute of Child Health, University College London, London W1T 3AA, UK, ${ }^{1}$ Department \\ of Obstetrics and Gynaecology, Rotunda Hospital, Dublin 1, Ireland, ${ }^{2}$ Department of Obstetrics and Gynaecology, University College London, London \\ W1T 3AA, UK and ${ }^{3}$ Program in Development and Fetal Health, Samuel Lunefield Research Institute, Mount Sinai Hospital, University of Toronto, Toronto, \\ Canada M5G 1 X5
}

(Correspondence should be addressed to P C Hindmarsh who is now at BEM Unit, Institute of Child Health, University College London, 30 Guilford Street, London WC1N 1EH, UK; Email: p.hindmarsh@ucl.ac.uk)

\begin{abstract}
Background: Low birth weight (BW), small head circumference, reduced length, increased preterm births and neuro-endocrine dysfunctions are among known consequences of smoking during pregnancy. Few studies have linked leptin to clinical features of growth restriction associated with maternal smoking and explored interaction with other determinants of size at birth, such as gender. Methods: Cord serum leptin concentrations were measured in 1215 term infants born to Caucasian mothers at completion of uneventful pregnancy. Serum concentrations were related to BW, gestational length, gender and maternal smoking and interaction with other determinants of size at birth evaluated.

Results: Smoking was more frequent in younger $(P<0.001)$ and shorter mothers $(P=0.03)$ from lower socio-economic groups (SEGPs) $(P<0.001)$. Infants born to smokers were lighter $(190 \mathrm{~g}$ less), shorter and with smaller head circumference. Cord serum leptin concentrations were higher in girls (9.8 S.D. $7.6 \mathrm{ng} / \mathrm{ml})$ than in boys $(7.05$ s.D. $5.8 \mathrm{ng} / \mathrm{ml})(P<0.001)$. Boys were heavier (BW 3.52 s.D. $0.49 \mathrm{~kg})$ than girls ( 3.39 s.D. $0.44 \mathrm{~kg})(P<0.001)$, but girls had greater skinfold thickness measurements (subscapular and quadriceps skinfold thicknesses 5.5 s.D. $1.6 \mathrm{~mm}$ and 7.6 S.D. $1.9 \mathrm{~mm}$ respectively; boys 5.3 S.D. 1.6 vs $7.24 \pm 1.90 \mathrm{~mm}, P<0.001$ respectively). Multivariate analyses showed gender $(P<0.001)$, BW SDS $(P<0.001)$, gestational length $(P<0.001)$ and maternal smoking $(P<0.042)$ as factors that influenced umbilical cord serum leptin concentrations in newborns.

Conclusion: Maternal smoking restrains foetal growth through placental vascular effects, and likely also via associated effects on leptin metabolism. More studies are needed to determine the influence that maternal smoking may have on placental syncytiotrophoblast and foetal adipose tissue.
\end{abstract}

European Journal of Endocrinology 159 217-224

\section{Introduction}

In 1957, Simpson described the association of maternal smoking with foetal growth restraint (1). Since then a series of studies have demonstrated a consistent effect of maternal smoking on foetal growth with reductions in birth weight (BW), length and head circumference. Moderate-to-heavy maternal smoking is responsible for an average reduction in BW of 90-200 g in infants whose mothers smoked during pregnancy (2). Foetal growth restriction is an important determinant of perinatal morbidity and mortality; and in the longer term, epidemiological studies suggest that intrauterine growth restriction predisposes to the development of the metabolic syndrome (the association of obesity, arterial hypertension, hyperlipidaemia, cardiovascular disease, impaired glucose tolerance and insulin resistance) (3).
Smoking during pregnancy has also been implicated in neurological endocrine as well as maturational modifications observed in infants born to smoking mothers (4).

The impact of maternal smoking on foetal growth arises in a number of ways either directly by reducing foetal growth as environmental toxin, by shortening gestational length $(1,5,6)$, thus increasing the incidence of premature births, or by altering uteroplacental and foetal blood flow, with consequent decrease in oxygen consumption, nutritional and energy supply to the foetus $(7,8)$. The classic measures of foetal growth, e.g. BW, are composites of a number of components each influenced to varying degrees by a series of growth factors. Longitudinal growth in utero is insulin-like growth factor-I (IGF-I) dependent and circulating concentrations of IGF-I are reduced in commercial use, distribution, and reproduction in any medium, provided the original work is properly cited. 
newborns born to mothers who have smoked during pregnancy (9). Other factors influence the development of adipose tissue, which is an important component of weight in the last 8 weeks of pregnancy.

Leptin, a 167 amino acid protein from the obese gene, is synthesized mostly in white adipose tissue but also in the placenta, and as a regulatory molecule of appetite it circulates at a concentration that is proportional to fat mass in both humans and rodents (10). A positive correlation between its cord concentrations, body weight and fat mass has been found in newborn infants (11), suggesting that leptin may play a role in the regulation of foetal adiposity.

The interaction of leptin with factors influencing foetal growth has not been determined and conflicting reports have been published on the impact of maternal smoking on cord serum leptin concentrations (12-15). In this report, we describe cord serum leptin concentrations in 1215 newborn infants born at term to Caucasian mothers and relate leptin values to BW, gestational age, gender and maternal smoking during pregnancy. Our aim was to answer the question of whether smoking during pregnancy, in addition to known mechanisms, also restricts foetal growth via its action on leptin metabolism.

\section{Subjects and methods}

\section{Study group}

The study cohort and our inclusion and exclusion criteria have been described elsewhere (9). The present study was confined to term-born infants (gestational age $>37$ weeks; gestational age was determined according to last menstrual date and/or the first obstetrical ultrasound). Maternal cigarette smoking was categorized as: never smoked (group 1, $n=870$ ), stopped on becoming pregnant (group 2, $n=117$ ), smoked less than 10 cigarettes/day (group 3, $n=115$ ), smoked 10-20 cigarettes/day (group 4, $n=90$ ) and smoked more than 20 cigarettes/day (group 5, $n=26$ ). Socio-economic status was determined from age at which full-time education was completed, marital status, occupation and partner's occupation, and social class assignment was made using the classification of the United Kingdom Office of Population Census and Statistics (Standard Occupational Classification Volume 3. OPCS 1991). Pregnancy complications were noted and infants excluded from analysis from those mothers who developed complications of pregnancy.

Complete perinatal outcome and anthropometric data (BW, length, head and mid-arm circumference) were available in 1484 babies. BW was measured using self-calibrating electronic scales (Seca, Birmingham, UK), length was measured using Infantometer (Child Growth Foundation, London, UK) and head circumference with a metal tape (Holtain,
Crymych, UK). Ponderal index was calculated as weight/length ${ }^{3}$ and skinfolds (triceps, sub-scapular and quadriceps) were measured using skinfold callipers (Holtain); three separate measurements were taken and the mean recorded. The coefficient of variation of the measurement error for length was $0.15 \%$ based on ten infants, each having been measured five times by three observers. Blood sample was collected after birth and before completion of the third stage of labour into EDTA from the umbilical vein. The sample was centrifuged, after cord blood $\mathrm{pH}$ was measured, separated and plasma stored immediately at $-20{ }^{\circ} \mathrm{C}$ until leptin assays were performed within 3 months of collection. The study received approval from the Research Ethics Committee of University College London Hospitals, and written informed consent for participation obtained from the mothers both for own participation and that of their newborn child after its birth.

\section{Leptin assay}

Serum leptin concentration was measured by commercial RIA (Linco Research Inc., St Charles, MO, USA). The within-assay coefficients of variation (CV) were 8.3, 3.9 and 3.4 at $4.9,10.4$ and $25.6 \mathrm{ng} / \mathrm{ml}$ respectively. The between-assay CV values were 5.6 and 6.3 at 3.5 and $15.5 \mathrm{ng} / \mathrm{ml}$ respectively. The calibrants in the assay were from purified recombinant human leptin. The minimum detection limit was $0.5 \mathrm{ng} / \mathrm{ml}$.

\section{Statistical analysis}

Anthropometric measures (BW, length and head circumference) were expressed as SDS using the 1990 British growth reference (16). Correlations between hormonal data and anthropometrics measures were estimated using Pearson's correlation coefficient. $\chi^{2}$ was used to compare the distribution of frequencies between groups. One-way ANOVA was used to determine differences between the mean values of the groups with Student-Newman-Keuls post hoc test to determine significance between groups. Multiple linear regression analysis was used to explore the effects of maternal smoking, infant's gender (male 1, female 2), BW (SDS), placental weight and gestational length on cord serum leptin concentration.

\section{Results}

\section{General}

In the study, 1650 mothers were enrolled and 1484 live infants were delivered, of whom 70 were preterm infants. Of the remaining 166 who did not deliver, 127 did not complete the study either because they had moved away or because they were lost to follow-up, 28 patients pregnancies were terminated either into 
miscarriage or by medical termination and 11 simply withdrew from the study. Analysis is therefore confined to 1215 term infants (gestational age $>37$ weeks) born to mothers whose pregnancies were uncomplicated by gestational diabetes, utero-placental hypoxia-ischaemia-antepartum haemorrhage, pregnancy-induced hypertension and pre-eclampsia. Clinical and anthropometric characteristics of mothers enrolled for this study are summarized in Table 1 and show that mothers who smoked heavily were younger (one-way ANOVA $F=27.4 ; P<0.001)$ and shorter $(F=2.64 ; P=0.003)$ and from SEGPs 4 and 5 (SEGP 1, 96\% non-smokers versus 56\% in SEGP 5; $P<0.001)$. Maternal body mass index was not significantly different between smokers and non-smokers. Smoking habit was not influenced by parity. No significant differences were found between groups with regard to maternal pre-gestation weight, weight gain during pregnancy (data not shown), gestation at first antenatal attendance, gestational age at delivery and blood pressure at first antenatal attendance or maternal haemoglobin.

Size at birth Neonatal anthropometric measures are summarized in Table 2. Overall, there were significant sex differences in BW, length and head circumference, with male infants being heavier, longer and leaner, and having larger heads than females. Infants born to mothers who smoked showed BW (a reduction of $190 \mathrm{~g}$ ), length and head circumference that were lower, compared with those of infants of non-smoking mothers $(P<0.05$ for groups 1 and 2 versus groups 3-5); differences between groups (smoking and nonsmoking) in these three parameters were not dose dependent.

Although no statistically significant differences could be observed between infants of smokers and those of non-smokers in skinfold thickness and mid-arm circumference, male infants had greater mid-arm circumference but smaller skinfolds than females. Fine analysis and comparison of BW between infants born to smoking mothers and those of non-smokers showed that frequency of babies with BW (SDS) below the third centile did not differ $\left(4.8 \%\right.$ vs $\left.2.8 \% ; \chi^{2} 6.37 ; P=0.17\right)$ between the two groups. There were, however, more babies with BW comprised between the third and the tenth centile born to smoking mothers when compared with non-smokers (19\% vs $\left.7 \% ; \chi^{2} 33.2 ; P<0.001\right)$.

Cord serum leptin concentration Table 3 compares cord serum leptin concentration, BW, ponderal index, triceps, sub-scapular and quadriceps skinfold thicknesses between sexes. Cord serum leptin concentrations were higher in girls than boys $(P<0.001)$; although the latter had higher BWs, girls had higher skinfold thickness measurements.

The effects of maternal smoking on cord serum leptin concentrations are shown in Fig. 1. There was no significant difference between the groups. The $P$ value for comparison of cord leptin concentrations in nonsmokers with the other groups is summarized in Table 4. Multiple regression analyses were then performed with umbilical cord serum leptin concentration as dependent variable, and infant's gender, BW (SDS), gestational length and maternal smoking during pregnancy as independent variables. BW $(P<0.001)$, gender $(P<0.001)$, gestational length and maternal smoking were of significant importance. Multivariate analyses with maternal smoking, placental weight, gender, gestational length and BW (SDS) showed that gender $(P<0.001)$, BW SDS $(P<0.001)$, gestational length $(P<0.001)$ and maternal smoking $(P<0.042)$ were the important factors that were associated with umbilical cord serum leptin concentration in newborns.

\section{Discussion}

This study was designed to assess the effects of maternal smoking during pregnancy on foetal cord serum leptin concentration at birth, in term infants, and hence answer the question of whether foetal growth restriction secondary to maternal smoking during gestation could result from the action of the latter on foetal leptin metabolism (Table 5).

Our results show effectively that factors associated with cord serum leptin concentrations in newborns are gender, gestational age, as well as smoking during pregnancy. Inaccuracy of self-reported smoking habits in comparison with cotinine assay by our study population is a likely criticism that may be made of this study. Biological assays, although more accurate, often provide

Table 1 Clinical and anthropometric details of mothers enrolled in the study.

\begin{tabular}{|c|c|c|c|c|c|}
\hline & $\begin{array}{l}\text { Non-smokers } \\
(n=868)\end{array}$ & $\begin{array}{l}\text { Stopped } \\
(n=117)\end{array}$ & $\begin{array}{l}<10 / \text { day } \\
(n=114)\end{array}$ & $\begin{array}{l}\text { 10-20/day } \\
(n=90)\end{array}$ & $\begin{array}{l}>20 / \text { day } \\
(n=26)\end{array}$ \\
\hline Age (years) & $31.8(5.3)$ & $31.2(5.1)$ & $27.6(5.7)$ & $27.9(5.8)$ & $27.5(5.3)$ \\
\hline Height $(\mathrm{cm})$ & $164.8(6.9)$ & $165.2(6.6)$ & $163.9(6.5)$ & $162.9(6.0)$ & $162.5(6.6)$ \\
\hline Weight (kg) & $63.8(11.1)$ & $64.1(9.2)$ & $63.2(10.4)$ & $62.2(11.8)$ & $65.8(17.7)$ \\
\hline $\mathrm{BMI}\left(\mathrm{kg} / \mathrm{m}^{2}\right)$ & $23.6(4.2)$ & $23.6(3.9)$ & $23.2(3.4)$ & $23.4(4.3)$ & $24.7(6.0)$ \\
\hline Gestation at delivery (weeks) & 39.7 (1.3) & $40.0(1.3)$ & $39.6(1.4)$ & 39.7 (1.2) & $39.5(1.4)$ \\
\hline
\end{tabular}

Data shown as mean with S.D. in parenthesis. 
Table 2 Newborn infants' anthropometric measures in relation to maternal smoking status.

\begin{tabular}{|c|c|c|c|c|c|c|}
\hline & $\begin{array}{l}\text { Non-smokers } \\
(n=868)\end{array}$ & $\begin{array}{l}\text { Stopped } \\
(n=117)\end{array}$ & $\begin{array}{l}<10 / \text { day } \\
(n=114)\end{array}$ & $\begin{array}{l}\text { 10-20/day } \\
(n=90)\end{array}$ & $\begin{array}{l}>20 / \text { day } \\
(n=26)\end{array}$ & $P$ \\
\hline BW & $0.18(0.96)$ & $0.04(0.87)$ & $-0.28(0.99)$ & $-0.23(0.95)$ & $-0.29(1.25)$ & $<0.001$ \\
\hline $\mathrm{BL}$ & $-0.08(1.11)$ & $0.03(1.24)$ & $-0.33(1.23)$ & $-0.48(1.16)$ & $-0.61(1.16)$ & 0.001 \\
\hline $\mathrm{HC}$ & $0.01(1.10)$ & $0.04(1.10)$ & $-0.38(1.10)$ & $-0.33(1.02)$ & $-0.29(1.37)$ & 0.001 \\
\hline TS & $5.8(1.5)$ & $6.2(1.7)$ & $5.7(1.6)$ & $5.8(1.6)$ & $5.8(1.8)$ & 0.06 \\
\hline SS & $5.4(1.6)$ & 5.5 (1.4) & $5.2(1.7)$ & $5.3(1.5)$ & $5.5(2.2)$ & 0.62 \\
\hline QS & $7.5(1.9)$ & $7.6(1.8)$ & $7.2(2.1)$ & $7.3(2.0)$ & $7.1(2.3)$ & 0.47 \\
\hline $\mathrm{MC}$ & $10.6(1.0)$ & $10.6(1.0)$ & $10.3(1.0)$ & $10.4(1.0)$ & $10.5(1.3)$ & 0.11 \\
\hline
\end{tabular}

Data are presented as mean with s.D. in parentheses, skinfold thicknesses expressed in mm. BW, birth weight; BL, birth length; HC, head circumference; TS, triceps skinfold; SS, sub-scapular skinfold; QS, quadriceps skinfold; MC, mid-arm circumference.

no precise information regarding quantities or timing of exposure. Moreover, some studies have reported good correlation between self-reporting versus cotinine assay and smoking effects on foetal growth $(17,18)$.

\section{Leptin and gender}

The gender difference in serum leptin concentrations previously reported by several other studies $(13,14,17)$ was also found in our study. Cord serum leptin concentrations were higher in girls than boys. It is tempting to speculate that, boys being heavier than girls, their body weight likely reflects heavier muscle bulk and skeleton, whereas higher leptin concentrations in girls are correlated with more subcutaneous fat. As this gender difference in body fat distribution is present as early as during antenatal life, we consider, like Jaquet et al. (19) that body weight at birth does not reflect body fat mass alone.

There are several explanations to the gender difference in cord serum leptin concentrations: for Tome et al. (20), the sex-based differences are not attributable to any growth-related differences between boys and girls, but may simply reflect a sex-based difference in the regional adipose tissue regulation of leptin production. For Bennet et al. (21), however, sexual dimorphism is probably the result of regional distribution of adipose tissue. Van Harmelen et al. (22) suggested that gender difference in leptin concentration was a consequence of variation in leptin secretion present in women and not in men. Like Nagy et al. (23), we think that the sexual dimorphism in cord serum leptin concentration is likely to be due to both relative body composition and fat distribution, which are different in male and female infants. The gender differences in cord leptin concentrations reported here are, however, not a constant finding in the literature, some studies have reported similar concentrations in boys and girls (13). The reasons for these discrepancies are yet to be elucidated.

\section{Effects of maternal smoking on placental circulation and foetal growth}

Effects of maternal smoking on placental morphology and function Active maternal smoking during gestation induces morphological changes with consequent reduction in both volume of maternal intervillous space and surface area of foetal capillaries (24), these changes lead to reduced oxygen diffusion across the placenta. Metabolites of cigarette smoke cross the placenta, passing from mother to foetus, and act as vasoconstrictors that reduce uterine blood flow by up to $38 \%(25)$. Of note is the fact that smoking hypoxia is not exclusively pre-placental in origin, but is complicated by both blood flow problems and cadmium toxicity that act at trophoblastic as well as other placental sites (26). Maternal smoking, therefore, places the foetus under chronic hypoxic stress, and hence contributes to restriction in weight gain, reduced length and small head circumference. Based on the model classifying the origins of hypoxia by Kingdom et al. (26), three principal classes are recognized: pre-placental, utero-placental

Table 3 Comparisons between boys and girls of anthropometric measures and cord serum leptin concentrations.

\begin{tabular}{|c|c|c|c|c|c|c|}
\hline Sex & BW (SDS) & Pondlnd. & Triceps SF & SSSF & Quad SF & Cord leptin \\
\hline Male & $\begin{array}{r}3.52(0.49) \\
(n=632)\end{array}$ & $\begin{array}{c}27.34(3.25) \\
\quad(n=613)\end{array}$ & $\begin{array}{r}5.77(1.60) \\
(n=577)\end{array}$ & $\begin{array}{r}5.28(1.54) \\
(n=576)\end{array}$ & $\begin{array}{r}7.24(1.90) \\
(n=573)\end{array}$ & $\begin{array}{r}7.05(5.84) \\
(n=474)\end{array}$ \\
\hline Female & $\begin{array}{r}3.39(0.44) \\
(n=586)\end{array}$ & $\begin{array}{c}27.57(3.14) \\
(n=575)\end{array}$ & $\begin{array}{r}5.86(1.50) \\
(n=527)\end{array}$ & $\begin{array}{r}5.48(1.60) \\
(n=527)\end{array}$ & $\begin{array}{r}7.62(1.87) \\
(n=521)\end{array}$ & $\begin{array}{r}9.77(7.60) \\
(n=442)\end{array}$ \\
\hline$P$ value & $<0.001$ & 0.236 & 0.348 & 0.032 & 0.001 & $<0.001$ \\
\hline
\end{tabular}

BW, birth weight; Pondlnd, ponderal index; Triceps SF, triceps skinfold thickness; SSSF, sub-scapular skinfold thickness; Quad SF, quadriceps skinfold thickness. Skinfold thickness in $\mathrm{mm}$ and cord leptin in $\mathrm{ng} / \mathrm{ml}$. Data shown as mean with s.D. in parentheses. 


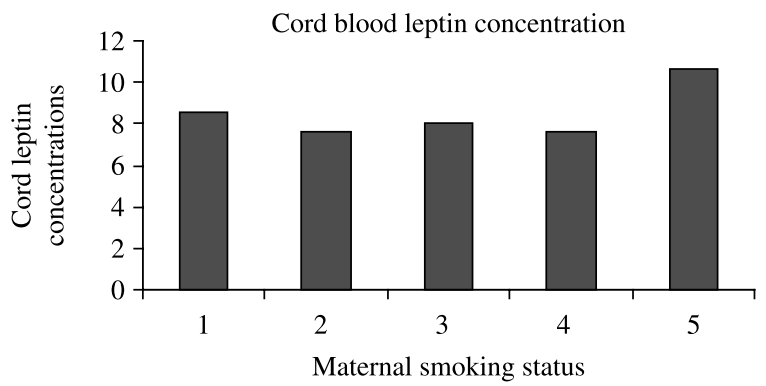

Figure 1 Cord leptin concentrations $(\mathrm{ng} / \mathrm{ml})$ according to maternal smoking status. 1, never smoked; 2 , stopped smoking; 3 , smoked $<10$ cigarettes; 4 , smoked 10-20 cigarettes; 5 , smoked $>20$ cigarettes/day.

and post-placental hypoxia. Maternal smoking would normally lead to the pre-placental type of this classification, in which there is reduced oxygen content in maternal blood. The study by Bush et al. (27) has, however, reported elevated maternal and foetal haematocrit levels in the smoking group, in addition to reduced mean BW in children. Within the placentas, these authors found increases in cadmium levels, in the relative volumes of maternal intervillous space and in the relative surface areas of foetal capillaries, and decreases in the relative and absolute volumes of foetal capillaries. These findings suggest that foetuses of smoking mothers are under hypoxic stress that could be, in part, due to the non-adaptative morphological changes found in the placenta. Smoking-induced hypoxia could, therefore, be both pre-placental and utero-placental.

Maternal smoking and foetal growth Effects of maternal smoking on foetal growth have been extensively studied $(1,6,9,28)$, low BW in children of smoking mothers is well documented, and our results confirm those of previous studies, with infants born to smoking mothers being $190 \mathrm{~g}$ lighter than those of nonsmoking ones. Our results are, in this respect, similar to those reported by Habeck et al. (28), with infants born to heavy smokers being the most growth restricted. Physio-pathological mechanisms underlying the effects of smoking during pregnancy on foetal growth are, however, only partially elucidated: impairment of foetal growth has been reported to result from altered utero-placental and foetal blood flow, and IGF-I axis as

Table 4 Cord leptin concentrations in relation to maternal smoking or non-smoking status.

\begin{tabular}{lrcc}
\hline Smoking status & $\boldsymbol{N}$ & $\begin{array}{c}\text { Mean cord } \\
\text { leptin (s.D.) }\end{array}$ & $\boldsymbol{P}$ value \\
\hline Never smoked & 657 & $8.53(6.90)$ & \\
Stopped smoking & 85 & $7.63(5.43)$ & 0.79 \\
Smoked $<10$ cigarettes & 82 & $8.03(7.20)$ & 0.97 \\
10-20 cigarettes & 74 & $7.60(6.26)$ & 0.81 \\
$>20$ cigarette & 18 & $10.63(11.72)$ & 0.70 \\
\hline
\end{tabular}

demonstrated in our previous study (9). Intrauterine growth restricted infants have recently been shown to have impaired growths of internal organ (small kidneys, liver and lungs), and it has been suggested that this could contribute to the occurrence of metabolic dysfunction in these children later in life (29). Bouhours-Nouet et al. have shown that smoking in pregnancy depletes placental mitochondria and induces respiratory chain complex III deficiency. Conjunction of these effects, likely, contributes to foetal growth restriction by limiting cellular energy availability to the foetus (30). In another study, Agostini et al. have reported that maternal smoking could also affect foetal growth by reducing docohexaenoic acid synthesis and/ or its maternal transfer to the foetus (31). With regard to compartments that contribute to the reduction in foetal size, contradictory research has been reported: total body electrical conductivity analyses and some anthropometric measurement studies have shown that growth restriction is predominant in the lean body tissues, with no changes in s.c. fat stores (32). Other studies have, however, suggested that generalized reduction in neonatal size affects proportionately fat and lean body masses (33). In a study of term-born appropriate for gestational age (AGA) infants, Clapp et al. (11) found fat mass to be the major morphometric determinant of cord leptin concentration. These authors also suggested that strong relationship existing between neonatal fat mass and BW on one side and weak relationship between it and neonatal fat-free mass on the other side were due to the large contribution made by fat mass to the variability in BW. In support to Clapp's findings is the fact that cord leptin concentrations are lower in small for gestational age (SGA) and preterm infants, known to have much less fat, in comparison with AGA and term-born infants (12). Regardless of conflicting reports on the body compartment that is most affected in growth restriction, it is likely that impairment in s.c. fat deposition is the major contributor to reduced foetal weight gain (34).

\section{Effects of maternal smoking on cord serum leptin concentrations}

Leptin is produced in the human placenta and secreted into both maternal and foetal circulations (35). The exact proportion of cord leptin that originates from foetal adipose tissue in comparison with that from placental production remains unknown. Estimations of placental leptin that is released into foetal circulation vary from 1.5 to $13.6 \%$ (36), the remaining proportion derives directly from foetal adipose tissue. During normal pregnancy, leptin has been shown to rise considerably in maternal circulation, followed by a rapid fall after parturition (35). Smoking probably influences both placental and foetal adipose tissue leptin production, although on a cord blood sample it 
Table 5 Placental weight and mother's body mass index (BMI) according to smoking status.

\begin{tabular}{|c|c|c|c|c|c|c|c|c|}
\hline \multirow{2}{*}{$\begin{array}{l}\text { Smoking } \\
\text { status }\end{array}$} & \multirow{2}{*}{$\begin{array}{c}\text { N } \\
\text { Lower bound }\end{array}$} & \multirow{2}{*}{$\begin{array}{c}\text { Mean } \\
\text { Upper bound }\end{array}$} & \multirow{2}{*}{$\begin{array}{c}\text { S.D. } \\
\text { Lower bound }\end{array}$} & \multirow{2}{*}{$\begin{array}{l}\text { Std. error } \\
\text { Upper bound }\end{array}$} & \multicolumn{2}{|c|}{$\begin{array}{l}95 \% \text { Confidence interval } \\
\text { for mean }\end{array}$} & \multirow{2}{*}{$\begin{array}{l}\text { Minimum } \\
\text { Lower bound }\end{array}$} & \multirow{2}{*}{$\begin{array}{l}\text { Maximum } \\
\text { Upper bound }\end{array}$} \\
\hline & & & & & Lower bound & Upper bound & & \\
\hline \multicolumn{9}{|l|}{ placwt } \\
\hline 1 & 778 & 673.23 & 129.240 & 4.633 & 664.13 & 682.32 & 320 & 1240 \\
\hline 2 & 99 & 668.37 & 135.743 & 13.643 & 641.30 & 695.45 & 400 & 1100 \\
\hline 3 & 89 & 667.03 & 120.568 & 12.780 & 641.64 & 692.43 & 400 & 990 \\
\hline 4 & 79 & 669.94 & 115.821 & 13.031 & 643.99 & 695.88 & 380 & 1000 \\
\hline 5 & 24 & 667.71 & 169.090 & 34.515 & 596.31 & 739.11 & 410 & 1160 \\
\hline Total & 1069 & 671.90 & 129.000 & 3.945 & 664.15 & 679.64 & 320 & 1240 \\
\hline \multicolumn{9}{|l|}{ BMI } \\
\hline 1 & 803 & 23.599 & 4.2150 & 0.1487 & 23.307 & 23.891 & 16.0 & 52.6 \\
\hline 2 & 113 & 23.620 & 3.8848 & 0.3654 & 22.896 & 24.344 & 18.2 & 45.7 \\
\hline 3 & 104 & 23.167 & 3.3893 & 0.3323 & 22.508 & 23.826 & 16.7 & 34.3 \\
\hline 4 & 84 & 23.371 & 4.2493 & 0.4636 & 22.449 & 24.294 & 18.0 & 44.8 \\
\hline 5 & 25 & 24.710 & 5.9604 & 1.1921 & 22.250 & 27.170 & 17.7 & 40.4 \\
\hline Total & 1129 & 23.569 & 4.1607 & 0.1238 & 23.326 & 23.812 & 16.0 & 52.6 \\
\hline
\end{tabular}

1, never smoked; 2, stopped smoking; 3, smoked < 10 cigarettes/day; 4, smoked 10-20 cigarettes/days; 5, smoked >20 cigarettes/day.

is not possible to differentiate the two. Further research is needed to clarify this.

Several studies have analysed the effects of maternal smoking on cord serum leptin concentration, with discordant results (11-14). In the study by Helland et al. (13), children of smoking mothers were lighter than those of non-smokers, plasma leptin concentrations were, however, similar between the two groups. For these authors, reduced BW in neonates of smoking women is not consequent to altered leptin concentration. Pardo et al. (12) also studied the effect of maternal smoking on leptin concentrations in term appropriate-for-gestational-age newborns, and reported similar leptin concentrations between infants of smoking and those of non-smoking mothers. Mantzoros et al. (11) have, however, reported that maternal smoking during pregnancy was associated with decreased cord leptin concentrations of both full-term and preterm newborns. For these authors, smoking during pregnancy induces reduction in foetal cord serum leptin concentration through depletion of foetal energy stores directly via substances present in tobacco smoke or indirectly by compromising nutrient supply consequent to induced placental changes. Another pathway through which smoking could influence leptin concentrations in neonates may be through decreased energy stores in foetal adipose tissue, probably via an increase in foetal catecholamine level. The later phenomenon is known to increase lipolysis. In another recent study by Ozkan et al. (14), maternal smoking has been shown to lower foetal plasma leptin concentration independently of BW. In our study, although comparison of cord serum leptin concentrations between infants born to smokers and those of non-smokers did not reach statistical significance (univariate analysis), multiple regression analysis performed with cord serum leptin concentration as dependent variable tends to suggest that infant's gender, BW, gestational length and maternal smoking during gestation were the more significant independent variables that influenced cord serum leptin concentrations. We have shown that BW SDS is significantly different between infants of smokers when compared with those of non-smokers; we could not, however, find statistically significant difference in cord serum leptin concentrations between the two groups (smokers versus non-smokers). Infants born to heavy smokers (>20 cigarettes/day) had cord serum leptin concentrations that were slightly higher; the reason for this discrepancy remains unexplained. The likely, but speculative explanations could be that these infants who were also the smallest (severe SGA), could have had enhanced endogenous steroidogenesis (secondary to chronic hypoxia) leading to an increase in leptin synthesis (37). Whether maternal smoking also restrains foetal growth by altering foetal leptin metabolism is not established with certainty, but this hypothesis cannot totally be ruled out.

Smoking during pregnancy deprives the foetus of nutrients and oxygen, resulting in episodic foetal hypoxia-ischemia and malnutrition. Smokinginduced foetal stress has been shown to be associated with raised amniotic fluid catecholamine concentrations, but studies have reported conflicting results in this regard, with some reporting increased amniotic levels (38) and others reporting lower cord catecholamine concentrations (39). That cigarette smoking during pregnancy could also impair foetal growth via leptin metabolism seems feasible, this would probably result from increased foetal lipolysis secondary to raised catecholamine concentrations. Systemic nicotine treatment in healthy men has, indeed, been shown to stimulate human adipose tissue lipolysis through local cholinergic and catecholaminergic receptors (40). 
Contribution of maternal smoking during pregnancy to foetal growth restriction, therefore, implies multifactorial physio-pathological mechanisms, some of which have been elucidated (IGF-I, placental changes, blood flow effects, etc). Nicotine-induced hypoxia has been extensively studied, cadmium toxicity acts at trophoblastic as well as other placental sites (26) and leptin is produced in large amounts by the syncytiotrophoblast (36); whether nicotine and/or cadmium toxicity impairs the expression of leptin mRNA here, needs to be studied further.

\section{Conclusion}

We have shown that maternal smoking during pregnancy restrains foetal growth, with infants born to heavy smoking mothers being the smallest. Our study also confirms the gender difference in cord serum leptin concentrations between boys and girls. Cord serum leptin concentrations, although slightly elevated in infants of heavy smokers, could not reach the level of significance. Multivariate analysis, however, points out gender, BW, gestational length and maternal smoking as most significant independent variables that influence cord leptin concentrations. We, therefore, think that maternal smoking also likely impairs foetal growth via its effects on leptin metabolism, in addition to wellknown placental vascular effects. Studies are awaited to analyse the effects of maternal smoking on both placental syncytiotrophoblast and foetal adipose tissue.

\section{Acknowledgement}

This work was supported by the British Heart Foundation (PG/98133 and RG2000015). We thank the midwives at University College London Hospital for their help in the construction of the Fetal Growth Study.

\section{References}

1 Simpson WJ. A preliminary report of cigarette smoking and the incidence of prematurity. American Journal of Obstetrics and Gynecology 195773 808-815.

2 Anderson GD, Blidber IN, McClemont S \& Sinclair JC. Determinants of size at birth in a Canadian population. American Journal of Obstetrics and Gynecology $1984 \mathbf{1 5 0} 36$.

3 Barker DJ, Hales CN, Fall CH, Osmond C, Phipps K \& Clark PM. Types 2 (non-insulin-dependent) diabetes mellitus, hypertension and hyperlipidaemia (syndrome $\mathrm{X}$ ): relation to reduced foetal growth. Diabetologia $19933662-67$.

4 Rantakallio P. A follow-up study to the age of 15 of children whose mothers smoked during pregnancy. Acta Paediatrica Scandinavica 198372 747-753.

5 Kyrklund-Blomberg NB \& Cnattingus S. Preterm birth and maternal smoking: risks related to gestational age and onset of delivery. American Journal of Obstetrics and Gynecology 1998179 1051-1055.
6 Hammoud AO, Bujold E, Sorokin Y, Schild C \& Bauman P. Smoking in pregnancy revisited: findings from a large population-based study. American Journal of Obstetrics and Gynecology 2005192 1856-1863.

7 Naeye R. Abruptio placentae and placenta previa: frequency, perinatal mortality and cigarette smoking. Obstetrics and Gynecology 198055 701-794.

8 Lehtovirta P \& Forss M. The acute effect of smoking on intervillous blood flow of the placenta. British Journal of Obstetrics and Gynaecology $1978 \mathbf{8 5} 729-731$.

9 Pringle J, Geary MPP, Rodeck CH, Kingdom JCP, Kayamba-Kay's S \& Hindmarsh PC. The influence of cigarette smoking on antenatal growth, birth size, and the insulin-like growth factor axis. Journal of Clinical Endocrinology and Metabolism $2005902556-2562$.

10 Rosenbaum M, Nicolson M, Hirsch J, Murphy E, Chu F \& Leibel RL. Effects of weight change on plasma leptin concentrations and energy expenditure. Journal of Clinical Endocrinology and Metabolism 199782 3647-3654.

11 Clapp JF \& Kiess W. Cord blood leptin reflects fat mass. Journal of the Society for Gynecologic Investigation 19985 300-303.

12 Mantzoros CS, Varvarigou A, Kaklamani VG, Beratis NG \& Flier JS. Effect of birth weight and maternal smoking on cord blood leptin concentrations of full-term and preterm newborns. Journal of Clinical Endocrinology and Metabolism 199782 2856-2861.

13 Pardo IM, Geloneze B, Tambascia MA \& Barros-Filho AA. Does maternal smoking influence leptin levels in term, appropriate-forgestational-age newborns? Journal of Maternal-Fetal and Neonatal Medicine 200415 408-410.

14 Helland IB, Reseland JE, Saugstad OD \& Drevon CA. Smoking related to plasma leptin concentration in pregnant women and their newborn infants. Acta Paediatrica $200190282-287$.

15 Ozkan B, Ermis B, Tastekin A, Doneray H, Yildirim A \& Ors R. Effects of smoking on neonatal and maternal serum and breast milk leptin levels. Endocrine Research 200531 177-183.

16 Freeman JV, Cole TJ, Chinn S, Jones PR, White EM \& Preece MA. Cross sectional stature and weight reference curves for the UK, 1990. Archives of Disease in Childhood 199573 17-24.

17 Verkerk PH, Buitendijk SE \& Verloove-Vanhorick SP. Differential misclassification of alcohol and cigarette consumption by pregnancy outcome. International Journal of Epidemiology $1994 \mathbf{2 3}$ $1218-1225$.

18 Klebanoff MA, Levine RJ, Clemens JD, Dersimonian R \& Wilkins DG. Serum cotinine concentration and self-reported smoking during pregnancy. American Journal of Epidemiology $1998148259-262$.

19 Jaquet D, Leger J, Tabone MD, Czernichow P \& Levy-Marchal C. High serum leptin concentrations during catch-up growth of children born with intrauterine growth retardation. Journal of Clinical Endocrinology and Metabolism 1999 84 1949-1953.

20 Tome MA, Lage M, Caminia JP, Garcia-Mayor RV, Dieguez C \& Casanueva FF. Sex-based differences in serum leptin concentrations from umbilical cord blood at delivery. European Journal of Endocrinology 1997137 655-658.

21 Bennett FI, McFarlane-Anderson N, Wilks R, Luke A, Cooper RS \& Forrester TE. Leptin concentration in women is influenced by regional distribution of adipose tissue. American Journal of Clinical Nutrition 199766 1340-1344.

22 Van Harmelen V, Reynisdottir S, Eriksson P, Thorne A, Hoffstedt J, Lonnqvist F \& Arner P. Leptin secretion from subcutaneous and visceral adipose tissue in women. Diabetes $1998 \mathbf{4 7} 913-917$.

23 Nagy TR, Gower BA, Trowbridge CA, Dezenberg C, Shewchuk RM \& Goran MI. Effects of gender, ethnicity, body composition, and fat distribution on serum leptin concentrations in children. Journal of Clinical Endocrinology and Metabolism 199782 2148-2152.

24 Andersen KV \& Herman N. Placenta flow reduction in pregnant smokers. Acta Obstetricia et Gynecologica Scandinavica 198463 707-709.

25 Suzuki K, Minei LJ \& Jonhson EE. Effects of nicotine upon uterine blood flow in the pregnant rhesus monkey. American Journal of Obstetrics and Gynecology 1980136 1009-1013. 
26 Kingdom JCP \& Kaufmann P. Oxygen and placental villous development: origins of fetal hypoxia. Placenta 199718 613-623.

27 Bush PG, Mayhew TM, Abramovich DR, Aggett PJ, Burked MD \& Page KR. A quantitative study on the effects of maternal smoking on placental morphology and cadmium concentration. Placenta $200021247-256$.

28 Habek D, Habek JC, Ivanisevic M \& Djelmis J. Fetal tobacco syndrome and perinatal outcome. Fetal Diagnosis and Therapy 2002 17 367-371.

29 Latini G, De Mitri B, Del Vecchiob A, Chitano G, De Felice C \& Zetterstrom R. Fotal growth of kidneys, liver and spleen in intrauterine growth restriction: 'programming' causing 'metabolic syndrome' in adult age. Acta Paediatrica 200493 1635-1639.

30 Bouhours-Nouet N, May-Panloup P, Coutant R, de Casson FB, Deschamps P, Douay O, Reynier P, Ritz P, Malthiery Y \& Simard G. Maternal smoking is associated with mitochondrial DNA depletion and respiratory chain complex III deficiency in placenta. American Journal of Physiology. Endocrinology and Metabolism $2005 \mathbf{2 8 8}$ 171-177.

31 Agostini C, Galli C, Riva E, Colombo C, Giovanni M \& Marangoni F. Reduced docohexaenoic acid synthesis may contribute to growth restriction in infants born to mothers who smoke. Journal of Pediatrics $2005147854-856$.

32 Lindsay CA, Thomas AJ \& Catalano PM. The effects of smoking tobacco on neonatal body composition. American Journal of Obstetrics and Gynecology 1997177 1124-1128.

33 Zaren B, Lindmark G \& Gebre-Medhin M. Maternal smoking and body composition of the newborn. Acta Paediatrica $1996 \mathbf{8 5}$ 213-219.
34 Yildiz L, Avci B \& Ingec M. Umbilical cord and maternal blood leptin concentrations in intra-uterine growth retardation. Clinical Chemistry and Laboratory Medicine 200240 1114-1117.

35 Masuzaki H, Ogawa N, Hosoda K, Matsumo T, Mise H, Nishimura H, Yoshimasa Y, Tanaka I, Mori T \& Nakao K. Nonadipose tissue production of leptin: leptin as a novel placenta-derived hormone in humans. Nature Medicine 19973 1029-1033.

36 Linnemann K, Malek A, Sager R, Blum WF, Schneider H \& Fusch C. Leptin production and release in the dually in vitro perfused human placenta. Journal of Clinical Endocrinology and Metabolism $2000 \mathbf{8 5}$ 4298-4301.

37 Parker CR, Buchina ES \& Barefoot TK. Abnormal steroidogenesis in growth retarded newborn infants. Pediatric Research 199435 633-636.

38 Divers WA Jr, Wilkes MM, Babaknia A \& Yen SS. Maternal smoking and elevation of catecholamines and metabolites in the amniotic fluid. American Journal of Obstetrics and Gynecology $1981 \mathbf{1 4 1}$ 625-628.

39 Oncken CA, Henry KM, Campbell WA, Kuhn CM, Slotkin TA \& Kranzler HR. Effect of maternal smoking on fetal catecholamine concentrations at birth. Pediatric Research 200353 119-124.

40 Andersson K \& Arner P. Systemic nicotine stimulates human adipose tissue lipolysis through local cholinergic and catecholaminergic receptors. International Journal of Obesity and Related Metabolic Disorders 200125 1225-1232.

Received 25 April 2008

Accepted 18 May 2008 